\title{
Microphotography and Cataloging: A Forecast
}

$\mathrm{T}$ HE IMPACT of microfilm upon cataloging may seem superficial to some, but to others it provides implications of important changes. The current problems of high unit cost of cataloging books and the mounting work loads are forcing catalogers to reorganize their routines and utilize new techniques. More specifically, control of the vast and ever growing body of published materials not adequately covered by the present centralized cataloging services is one of the major problems facing college and university cataloging staffs. Some catalogers may consider the microfilm as merely an added burden, but others regard it speculatively as a possible new tool.

In current professional literature, many writers advocate an extension of centralization in cataloging, either by cooperative arrangements between colleges and universities or by commercial methods. The cry heard on every hand is: "Let there be printed cards for all books," and "Let the cards come with the books." Should cards come with all films, as well? In the future, might cards and films be integrated, in some new form of publication?

Against the background of the general problems which face catalogers, the specific topic-that of cataloging microfilm and associated materials-may seem a minor matter, at least at present. If the task is considered from the routine point of view, it can be said :

Treat the film as a book. Make a regular catalog card for the item contained on the strip of film and add a few notes covering the form in which the material appears. State that the item is on a film, which is so many millimeters wide; that it is a negative (or a positive print); that there are so many "frames" or exposures on the film, with the text reproduced one or more pages to the frame, and the lines of type running with or across the long way of the film (this last information being conveyed in code form with the words "placement I, II," or "III"). Also give credit to the institution owning the film which is reproduced or to the book of which the film was taken. These items of information are those requested by the Philadelphia Bibliographic Center in compiling the Union List of Microfilms. The inclusion of this information on the catalog card should adequately complete the matter of physical description and should provide all necessary help to the patron in the use of the film in a projector. From the subject point of view, full contents notes, which give a clue to the material contained in each reel, are probably needed by the patron. Form subject added entries and/or a separate card list of microfilms would also prove helpful. Since the film itself is in a box or a filing cabinet somewhere, a call number indication of its location must be provided. Then, to make the shelflist complete, the item could be closely classified and a card provided in the appropriate place, so that searchers using this tool should not be disappointed. Also, a dummy of the item filmed could be placed in the book stacks or vertical file so that patrons looking in those places would be rewarded.

By this time, at least, the average cataloger may feel overwhelmed. Yet each item on this list has been advanced in the literature for inclusion in the routine for handling microfilm. Can all of it be done? Is it all necessary? Is any of it 
necessary? Since catalogers, as a group, do not agree about methods or even about certain fundamental aims and purposes, it is difficult to answer these questions, even the last one. Shall the film be thought of as not just another book but as something quite different-because of its form, the uses to which it is put, and the type of service it is capable of rendering?

\section{Materials Filmed}

The types of materials which are filmed and with which librarians deal may be considered. Generally speaking, a university will buy film when it is cheaper to do so than to obtain the original book or periodical, or when it is impossible to obtain it. When the expected use is heavy, enlarged prints or photostats will be preferable to film, but, in the case of lengthy research items, film is desirable because of its smaller bulk and lower cost. At present there are certain major categories of film: newspapers and serial publications photographed in long runs; old, out-of-print, and rare books, usually unobtainable in the original by the average institution; and a miscellaneous hodpepodge of theses, manuscripts, maps, and articles from serials. Newspapers and other serials, when considered as units and not analyzed, present no new problems. Rare books, as such, deserve careful treatment and justify the expenditure of time by the cataloger; cards for such items are increasingly available from centralized cataloging undertakings. In the beginning the cataloging of films of these materials may follow in the pattern of our present handling of the originals.

But what about the third group? A start is being made in the centralized handling of doctoral dissertations by the Microfilm Abstracts project. But there is nothing to help with periodical articles, which come frequently as a substitute for the interlibrary lending of originals. At this point there is trouble. If these items are handled as analytics-and the decision on this point is a matter of institutional policy-then considerable work results. Side by side with the problem of reprint via film, there is that of the "publication" of manuscript material. The recent phenomenal increase in the bulk of near-print publications, issued in small editions, indicates something of what may be expected from this quarter.

\section{The Rider Book}

It might be profitable at this point to refer to an important recent book: Fremont Rider's The Scholar and the Future of the Research Library. In it, Mr. Rider makes a frontal attack on the problem of handling the types of material under discussiontheses, manuscript material, maps, ephemeral publications of small editions, and serial publications; all research material, most of it of limited use. Yet so important does $\mathrm{Mr}$. Rider believe the need for detailed cataloging of these items, that he advocates centralized handling of such materials to effect a publication or republication in microprint form on catalog cards. Serials would be analyzed, one article to a card. This is a significant matter, since the process is essentially one of modifying the present methods of microreproduction with the object of incorporating the benefits of centralized cataloging. The form of the card which Mr. Rider advocates is also worth noting. First of all, there is no call number and no numerically expressed classification, since the book is on the back of the card. The subject of the item is indicated in a "classificational subject heading" printed at the top of the card at first indention. Instead of the present classification systems expressed in numerical notation, Mr. Rider would use one utilizing word notation. In 
place of the present alphabetical subject catalog he would use a printed index in book form, similar to Dewey's "relativ index."

The next thing which strikes the cataloger is the fact that the microcard is a true unit card. No added entries are to be supplied by typewriter. By widely separating the indention and by varying the type face of the three entry lines, which indicate the subject classification, the author, and the title, Mr. Rider believes that recognition of the entry will be automatic to any patron who flips over a few cards in the file. It may be added parenthetically that underlining the entry letter with red ink would permanently "locate" the card.

\section{Useful Information}

Third, each card bears an annotation and a vita, which give consistently more information of a kind useful to the research worker than is provided in our present code for routine cataloging. Since the text itself is reproduced in miniature on the reverse of the card, the bibliographic description can be shortened and simplified, thus reducing cost.

With the microcard, true centralized cataloging and cataloging at the publishing level are provided. In other words, the cataloger has something to say about the form of the published item, taking advantage of the money- and timesaving features of mass reproduction. Each university would be supplying copy in its chosen field of concentration, to be edited and published in its own plant or, in cooperation with other institutions, at central laboratories. Mr. Rider would literally have us all participating in this new cataloging-publishing venture.

At this point the weary cataloger will say: "What about all this saving us time? Look at the bulk of the Union List of
Serials. How long do you think it will take us to wade through that, analyzing everything?"

Under any plan of cataloging, such a program would take many years. But, under any plan of centralized cataloging, time is usually saved. Translated into budgetary terms, the saving of catalogers' time is a major saving of money for libraries in the aggregate. Furthermore, if the most-used serials are handled first (and usestudies already made can be utilized as guides in this), the time elapsing before accomplishing reasonably complete coverage in many fields may be less than believed.

\section{Microcard Suggestions}

But what about the present? Microcards are still just a topic for discussion. Can a start be made? Present microfilm equipment, for example, can be used to experiment. Several writers have advocated that short strips of microfilm be mounted on catalog cards and filed by an entry typed in the usual way on the front of the card. The card could then be read in a Readex machine (an easier procedure for the patron than using a projector). Using this idea as a starting point, a modest program of institutional publication of certain items of limited use could be worked out. Master's theses rarely circulate in carbon copy form outside the walls of originating institutions. The thesis of average length can be filmed in the unbound state for a dollar or two. The resulting five feet of film (average) can be cut into twelve strips, trimmed, and mounted three together at a time in a printing frame to make positive prints, the size of a catalog card, containing twentyfour pages of microtext. On the unsensitized sides, a catalog entry for the item could be mimeographed. This would include an annotation, or abstract of the thesis, and a vita. Total cost may be esti- 
mated at something under ten cents a card, including labor and materials for filming, printing, and cataloging, in an edition of thirty copies. Larger editions and blanket subscription arrangements would reduce costs slightly. This total cost of forty or fifty cents a title would be only a little higher than the cost of an interlibrary loan for the bound book. If desired, sets of "regular" catalog cards to accompany the photocards could be mimeographed at the same time at little extra cost.

Not only theses but out-of-print titles in university serial publications and all sorts of material previously denied publication because of high costs could be issued. It might prove more economical if material to be filmed, with its catalog card copy, could be sent from several institutions in an area to a single central laboratory for processing. Wilson and Tauber, in The University Library, suggest such a laboratory for the Los Angeles area.

\section{Group Publishing}

It is not wise to confine thought to one style of technique. Catalogers think largely in terms of cards, though they use book-style catalogs and bibliographies as a matter of course and as a matter of preference when a choice is offered between books and cards. For many years, the Wilson cumulative indexes have been a boon to libraries. The development of mimeographing, miniature printing, and other low-cost methods of reproduction has made book catalogs increasingly practical for many uses. It is possible to contemplate a program of handling serial publications which would use the filming of continuous runs of text, accompanied by book catalogs similar to the Wilson periodical indexes. Publications could be filmed and published in groups. For example, serials in the field of organic chemistry which were not widely distributed in the original could be handled as a block. Nor would the plan restrict itself to serials. All dissertations in the field of education could be reduced to film and issued annually in one alphabet, on a few large reels, and indexed in a single volume. The cost of film and index should be only a fraction of that of the publications alone, as originally issued. The main difficulty would be in handling film. Special projectors, with high speed rewind, and provision for stroboscopic indexing of the film itself would be necessary.

Such a program would be larger in unit scale than the microcard one and would raise problems of commercial backing and publication. Since films, not books, would be forwarded with the index copy to the central "publishing" plants, the handling of materials would not prove difficult. In essence, the plan would not be as flexible as that of microcards, and would be harder to keep up to date-a fact that would not enter into the matter of issuing older titles.

\section{Other Suggestions}

In the July 1945 issue of the Library Quarterly, Ralph Eugene Ellsworth outlines a proposed book type national union catalog, with annual supplements and a parallel series of subject bibliographies in book form. Following this idea, there appeared in the November 1945 A.L.A. Bulletin an article on "Microbibliography: A Possible Alternative to Microcards" by Edwin E. Williams. He proposed subject bibliographies with "supplements containing the full text in microprint of all the materials they list." This idea, also, is capable of further development. Why not reprint groups of serials or similar materials, as suggested above, in book form rather than on film? If the cost could be brought down from the present Readex price of more than fifty cents a sheet to ten cents, 
the text of the approximately seven thousand dissertations normally purchased by a large university library during the year could be available in ten quarto loose-leaf volumes costing a hundred dollars a volume. The format and degree of reduction assumed here is that used in the present Readex process. Greater reductions are foreseen by Fremont Rider and others. Should they be achieved, possibilities would increase tremendously. If space were the only factor to be considered, the proposed national union catalog, by tripling its contemplated size of 1900 volumes, could include not only the catalog cards for all books in the United States but the microtext of all the books as well.

\section{Indexing}

Whatever form microphotography may take in the future, those who forecast its growth and development also forecast a parallel development of centralized indexing in a form not interfilable in the present card catalog (and this applies to microcards, if one looks at the matter practically). This is a trend that scholars and librarians may deplore but it is determined by economic necessity. If research materials are distributed, they should be indexed, but the amount of use to which these materials will be subjected does not justify adoption of the present costly methods of piecework cataloging. Undoubtedly, there will always be items not included in the large, centrally issued blocks of micro-materials; these can only be handled as separate cards or reels, as is now done. It is to be expected, however, that the cataloging of such items will be patterned-after that of other large compilations of microprint and not after the style of the present card catalog. It may be that the library will issue book catalogs of its own unique items or prepare cards interfilable with the unit style microcards.
The writer is aware that this point is debatable. For example, Keyes D. Metcalf, in the Library Journal of Sept. I, I945, asserts: "If microcards are filed separately, a catalog card for [each one of] them must be in the regular catalog and that of course adds to the expense." At the present time, the cards for a small group of "rare book" or "manuscript" films would be lost if not in the main catalog. But, one may inquire, is a card in the main public catalog now deemed necessary for every government document, for every periodical article now indexed by the Wilson services? Is it too much to expect that the research worker of the future shall look in two or more files rather than in one? Whatever decision is made about the desirability of extending double cataloging coverage, an arbitrary division of materials will almost inevitably be effected. The matter of cost, it would seem, is a decisive factor here, as well as the large-scale development of the new medium.

\section{New Processes Developed}

The war interrupted the development of the use of microphotography in libraries just at the point where it was ceasing to be merely an auxiliary to the other, principal categories of material. The development of new technical processes in the field, however, was stimulated by wartime needs. No doubt new processes and devices will appear shortly on the market ready for use. It is not difficult to foretell that the use that libraries make of the new techniques will be determined to a large extent by the cooperation of catalogers. The economies and increase in volume of service made possible by microphotography will be in large part nullified if we persist in adding a dollar cataloging charge to the cost of each item.

Whatever is done in planning the future 
of cataloging of microfilm and related materials, two things should be kept in mind: First, it must be decided what type of service catalogs are to render and what type of patron is to be served principally. Probably, we shall incline more and more to the subject approach-at least, in current largescale cooperative cataloging projects more attention is being paid to this kind of detail than was before felt necessary. For the full coverage of a book from the subject point of view, we may have to wait, however, for some device such as Vannevar Bush's filmed catalog cards, with code indicators in dot form, to be scanned at tremendous speeds by photoelectric eyes and rephotographed on the fly by high-speed cameras to form films of selected cards for the formation of bibliographies.

\section{New German Library_Service}

\section{(Continued from page 225)}

The principal questions Predeek's card catalog was prepared to answer were: (I) Who was doing research in what field? (2) What had been the results of previous research? Information would be furnished free of charge. The fields covered were general science, engineering, medicine, agriculture, and forestry. In fields adequately covered elsewhere, notably chemistry and mining, the card index was to supply only supplementary data. Extension of coverage to the social sciences and humanities was contemplated.

How effective the Kartei was in aiding the Nazi war effort could not be ascertained from the sources at hand. Had such a research information service been available earlier in the war, it would undoubtedly have helped to expedite emergency research
The second thing that should be remembered is this: The only device yet evolved to avoid duplication of work and multiplication of the costs of cataloging is centralized and cooperative cataloging. Once standardization of approach is achieved, this shall follow. In the meantime, so long as there remains this chaos of varying sizes of film, types of projector equipment, methods of housing and storing materials, there will exist the problem of hand-typed, custommade cards, tied to the present card cataloging system. It is only when microphotography can break away from the present routines that the fullest measure of independent and efficient service can be rendered, as independent as the government document collections but much more versatile, supplementing and, in part, even supplanting them.

in Germany. It was an attempt to avoid duplication of effort and to coordinate scientific research activities on a national scale, but it came too late in the game to be of much value.

Several facts seem significant concerning this German venture in research library service: ( 1 ) at a time of critical shortage of personnel and materials, library techniques received recognition as indispensable tools in an important governmental enterprise; (2) professionally trained library personnel was recruited for key positions within the framework of science and technology; (3) bibliographic investigation was deemed so essential a phase of scientific research that a special administrative unit was established and substantial funds appropriated for accomplishing the work. 